\title{
Evolução da terapia de voz para idosos com e sem estimulação elétrica neuromuscular
}

\section{RESUMO}

Introdução: O declínio da qualidade vocal, que ocorre durante a fase da senescência, impacta diretamente no convívio social e na qualidade de vida dos idosos. As terapias vocais para idosos com foco na fisiologia do exercício e estimulação elétrica neuromuscular possuem potencial para promover ajustes fisiológicos, a fim de melhorar os déficits causados pelo envelhecimento. De maneira geral, encontramos avaliações nos momentos anteriores e após as terapias, porém, raros são os estudos que analisam a evolução diária das terapias que podem contribuir para a compreensão dos efeitos durante a aplicação dos procedimentos. Objetivo: Analisar a evolução diária dos aspectos perceptivoauditivos da voz de idosos submetidos à terapia com progressão de intensidade e frequências vocais e duração do tempo de fonação, além de verificar se há diferenças quando a terapia é realizada com ou sem estimulação elétrica associada. Métodos: Este projeto foi aprovado pelo Comitê de Ética em Pesquisa da Faculdade de Odontologia de Bauru, sob o parecer número 2.576.172. Trata-se de um estudo de análise prospectiva, randomizado e cego, onde três juízes fonoaudiólogos foram responsáveis por analisar a qualidade vocal de vozes de 30 idosos com queixa vocal e características de presbilaringe, divididos em dois grupos: grupo que recebeu apenas a terapia com progressão de intensidade e de frequência vocal e de duração do tempo de fonação (GT); e outro grupo que recebeu a mesma terapia associada à estimulação elétrica neuromuscular $(\mathrm{GT}+\mathrm{E})$, utilizando o aparelho VitalStim ${ }^{\circledR}$. Foram comparados os momentos antes e depois de cada uma das 12 sessões terapêuticas, considerando análise perceptivoauditiva dos parâmetros grau geral, rugosidade, soprosidade e projeção vocal da vogal sustentada e da fala encadeada. Para a análise estatística foram utilizados os testes de coeficiente de correlação intraclasse, que foi aplicado para mensurar a força da confiabilidade inter e intra-avaliador, bem como foi utilizada a Análise de variância com três fatores e teste Tukey $(p<0,05)$. Resultados: Os valores do momento pós foram menores que os do pré, com diferença estatística significativa, considerando todos os grupos e todas as sessões, nos parâmetros: Grau geral para fala encadeada e vogal sustentada; soprosidade para a vogal; e projeção prejudicada para vogal e fala encadeada; no grupo GT>GT+E nos parâmetros de soprosidade da fala encadeada e projeção vocal da vogal. Na comparação entre os grupos foi observado: GT<GT+E no parâmetro rugosidade da vogal, independente de momento ou sessão. Foi encontrado ainda, na análise da interação momento e grupo, GTpré >GTpós para o parâmetro grau geral da vogal; e na interação momento/sessão, no parâmetro projeção vocal prejudicada, T1 pré>T1 pós, T3pós, T7pós, T11pré e T11pós. Conclusão: A projeção vocal foi o parâmetro que indicou a evolução por sessões, uma vez que houve melhor projeção vocal no momento pós de diversas sessões em relação ao momento pré da T1, além de ter sido o único parâmetro a indicar melhora específica em sessões pré, isto é, T11 melhor do que T1. Considerando os dois grupos conjuntamente e o total de sessões, houve diminuição dos valores dos parâmetros de grau geral, soprosidade e projeção vocal no momento pós. Não houve diferenças na evolução terapêutica quando o tratamento vocal em idosos foi realizado com ou sem estimulação elétrica associada.

Palavras-chave: Distúrbios da voz, Treinamento vocal, Estimulação elétrica. 